\title{
Cytokines - major molecular messengers orchestrate between inflammation and cancer
}

\author{
Shrihari T.G
}

Department of Oral Medicine, Oral Biology and Immunology, Krishna Devaraya College of Dental Sciences and Hospital, Bangalore, Karnataka, India

\begin{abstract}
Inflammation is the defensive mechanism against physical or chemical or thermal or infectious agents. Acute inflammation is a protective mechanism against any noxious stimuli by various mediators such as cytokines, chemokines, enzymes, growth factors by inflammatory cells. If the inflammation is aggrevated chronically, smouldering inflammation results in release of inflammatory mediators such as cytokines, chemokines, growth factors, proteolytic enzymes, from innate and adaptive immune cells results in tumor initiation, tumor promotion and tumor progression. Cytokines are intercellular molecular messengers between immune cells and cancer cells, synthesized from immune cells and stromal cells activate transcription factors bring about tumor progression by cell proliferation, cell survival, angiogenesis, genomic instability, epithelial to mesenchymal transition, invasion and metastasis. This article briefs about the role of IL-1, TNF- $\alpha$, IL-6, IL-8, IL-10, TGF$\beta$, and IL-17 cytokines in progression of cancer.
\end{abstract}

Eur Res J 2018;4(3):140-144

Keywords: Interleukin-8, interleukin-10, TNF- $\alpha$, TGF- $\beta$, STAT-3, NF-кB

\section{Introduction}

Most of all solid tumors have inflammatory cells and their mediators in their tumor microenvironment. External environmental factors play a very important role in cancer. Inflammatory mediators in tumor microenvironment promote tumor initiation, promotion and progression. Chronic inflammatory conditions induced tumor progression are ulcerative colitis and Crohn's disease induced colorectal cancer, hepatitis B and C induced hepatocellular cancer, chronic periodontitis induced oral squamous cell carcinoma, oral potentially premalignant conditions (Lichen planus and oral submucous fibrosis) induced oral squamous cell carcinoma, prostatitis induced prostate cancer, hPV induced oropharyngeal carcinoma and cervical cancer, smoking induced lung carcinoma, gastric cancer associated with chronic gastritis (H. Pylori), esophageal cancer associated with Barret's esophagitis, gall bladder carcinoma associated with chronic cholecystitis, endometrial carcinoma associated with endometriosis. Chronic inflammation is considered as a seventh hallmark of cancer.

Interleukins are intercellular messenger molecules discovered in the 1970. Cytokines develop a specific immune response to a target antigen by 


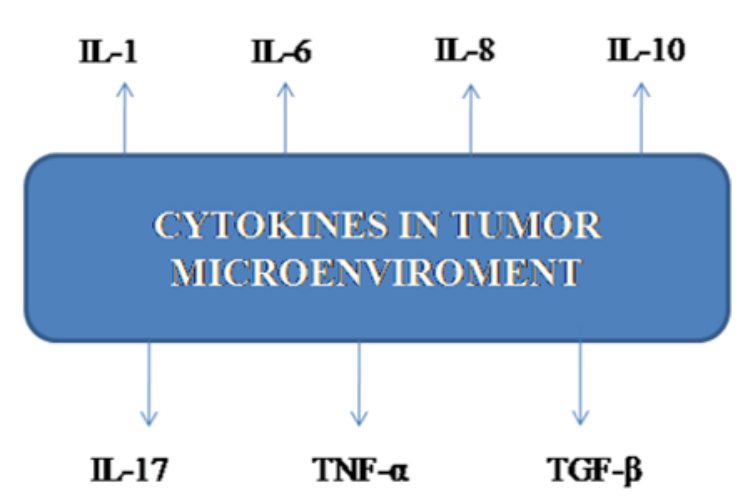

Figure 1. Cytokines in inflammatory tumor microenvironment are IL-1, TNF- $\alpha$, TGf- $\beta$, IL-6, IL-8, IL-10 and IL-17.

communicating cells of the immune system $[1,2]$.

Interleukins are secreted by immune cells such as CD4 T helper cells, monocytes, macrophages and endothelial cells. They attach to a surface specific cell receptor, triggers a cascade of events in the target cell alters cell behavior. Interleukins also has immunomodulatory functions through maturation, migration, differentiation and adhesion of the cells of the immune system [3].

In inflammatory microenvironment recruit immune cells produce cytokines, chemokines, growth factors, activate transcription factors such as NF- $\mathrm{B}$, STAT-3, recruit chemokines, cytokines, prostaglandins activate transcription factors such as NF- ${ }_{\mathrm{K}} \mathrm{B}$, STAT-3, from cancer cells involved in cell proliferation, cell survival, angiogenesis, genomic instability, epithelial to mesenchymal transition, invasion and metastasis. Cytokines are involved in pro-inflammatory or antiinflammatory action depends on cytokine concentrations, expression of cytokine receptor content, state of activation of surrounding cells. They stimulate stromal and immune effector cells at tumor site and enhances cytotoxic effects of immune cells to tumor cells. Recent studies has shown that interleukins have major role in tumor driven molecular mechanism. Tumor as it progress and evolve, they evade by the immune system recognition by recruiting inflammatory cells secretes various cytokines in tumor microenvironment, which in turn stimulates biomarkers such as transcriptional factors involved in induction of EMT (Epithelial to mesenchymal transition) markers, anti-apoptotic molecules and cancer stem cells. Cytokines such as TNF- $\alpha$, TGF- $\beta$, IL-1, IL-8, IL-10, IL-6and IL-17 creates a conducive inflammatory environment of tumor driven immunosuppression, tumor growth and metastasis [46] (Figure 1).

\section{Cytokines in tumor microenvironment}

Cytokines secreted by immune cells involved in tumor progression by promoting cell proliferation, angiogenesis, genomic instability, cell survival, immunosuppression, invasion and metastasis (Figure 2).

IL-1 is a pleotropic cytokine are of two subtypes IL- $1 \alpha$ and IL-1 $\beta$ with encoding two separate genes have an identical biological activity through same receptor complex produce by variety of cells such as monocytes, macrophages, keratinocytes and endothelial cells activate $\mathrm{T}$ cells and B lymphocytes.

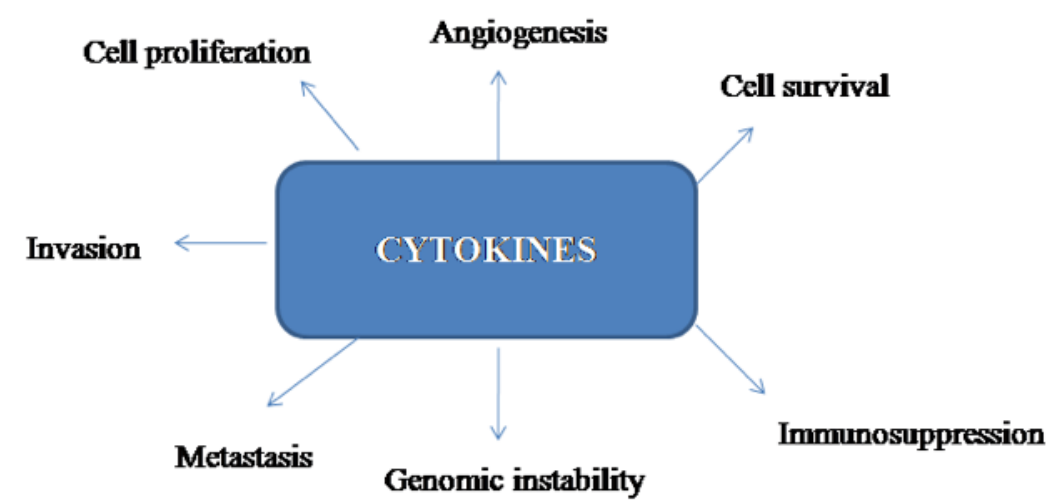

Figure 2. Cytokines secreted by immune cells involved in tumor progression by promoting cell proliferation, angiogenesis, genomic instability, cell survival, immunosuppression, invasion and metastasis. 
IL- $1 \alpha$ is localized in cell membrane, cytosol and regulates intracellular microenvironment binds to IL1R1 expressed in most cell types and responsible for IL-1 signal transduction. IL-1 $\beta$ is located extracellularly binds to IL-R11 present on neutrophils, monocytes, B lymphocytes and decrease signal transduction of IL-1 produced by human cancer cells. IL-1 $\beta$ activates NF-K $\mathrm{B}$ a key transcriptional factor, which inturn induce expression of IL- 8 , TNF- $\alpha$, VEGF, IL- 6 and TGF- $\beta$ promotes tumor progression in various human cancers. This protein acts through induction of prometastatic genes such as MMPs, angiogenic proteins and growth factors such as VEGF, IL-8, IL-6, TNF- $\alpha$ and TGF- $\beta$, further activates MAPK-AP-1, NF-K $\mathrm{B}$ and P13/AKT signaling pathway, promote tumor growth and metastasis in several human tumors such as melanoma, head and neck squamous cell carcinoma, colon, lung and breast cancer [7-9].

IL-6 is a potent inflammatory cytokine, it is a key growth promoting and anti-apoptotic factor, produced mainly by macrophages, dendritic cells, and B lymphocytes as well as fibroblasts, epithelial cells and endothelial cells. IL-6 stimulates target cells via binding to IL-6R activates transcriptional factor STAT3 acts on malignant cells. It also increases VEGF expression involved in angiogenesis, cell proliferation, cell survival, invasion and epithelial to mesenchymal transition in head and neck cancer cells and increasing their metastatic potential in human cancers such as oral squamous cell carcinoma, gastric cancer and multiple myeloma [10-12].

IL- 8 is a cytokine produced by macrophages, epithelial cells also known as neutrophil chemotactic factor induced by variety of stimuli are LPS, cytokines such as IL-1, TNF- $\alpha$ and bacterial or viral products. Transcriptional factor such as $\mathrm{NF}_{-\mathrm{K}} \mathrm{B}$ is an essential for IL-8 expression was dependent on hypoxia, cellular stress, nitric oxide (NO), acidosis, and a potent promoter of angiogenesis, aggressive growth and metastasis in many human cancers such as head and neck cancer, breast, cervical, prostate, colon, gastric, lung, melanoma, brain, mesothelioma, ovarian cancer and hematological malignancies such as AML, CLL and Hodgkin's lymphoma [13-16].

IL-10 is secreted by alternatively activated T cells phenotype (Th2 cells) acts on macrophages, T cells, B cells, monocytes, dendritic cells, granulocytes, and mast cells inhibits antigenic cell presentation, cell maturation and differentiation allowing evasion of immune surveillance by tumor cells and cytokine production acts as immunosuppressive and antiinflammatory role. It inhibits the activation of transcription factor $\mathrm{NF}_{-\mathrm{K}} \mathrm{B}$ and stimulating STAT3 activation, there by inhibiting pro-inflammatory cytokine production such as TNF- $\alpha$, IL-6, and IL-12. It has also shown to modulate apoptosis, angiogenesis suppression and pro-tumorigenic effect in cancers such as in B cell lymphoma prognosis is poor, promotes head and neck cancer and Burkitt's lymphoma [17-20].

TNF- $\alpha$ involved in chronic inflammatory diseases induced carcinogenesis by promoting angiogenesis, invasion, tumor progression have been demonstrated. It is produced by tumor and stromal cells or inflammatory cells such as macrophages, T cells, B cells and endothelial cells in tumor microenvironment, promotes cancer cell survival by induction of $\mathrm{NF}_{-\mathrm{K}} \mathrm{B}$ encoding genes dependent anti-apoptotic molecules such as BCL-2, BCL-XL, surviving, CFLIP, and TRAF1/2. TNF- $\alpha$ dependent tumor promotion based on direct oncogene activation and generation of genotoxic molecules such as reactive oxygen species (ROS) and reactive nitrogen species (RNS), induce DNA damage and mutations, facilitating tumorigenesis. Other actions of TNF- $\alpha$ include immunosuppression of $\mathrm{T}$ cell response, cytotoxic activity of macrophages, and promotion of angiogenesis by its ability to cause differentiation of myeloid progenitor cells in to endothelial cells in tumor microenvironment. Pro-tumoral activity of TNF- $\alpha$ mediated via TNFR1 receptor found on tumor and stromal cells, whereas, TNFR2 receptor found on leucocyte infiltrate, stimulating autocrine growth, acting via cross talk between EtK-VEGFR2. TNF-• also promotes metastasis by inducing epithelialmesenchymal transition (EMT) and found elevated in plasma of patients with advanced cancer, which helps in prognostic purpose in many cancers such as head and neck cancer, lung carcinoma, skin cancer, ovarian cancer [21-23].

TGF- $\beta$ is a pleotropic immunosuppressive and anti-inflammatory cytokine produced by tumor cells, stromal cells, including cancer associated fibroblasts and immune cells such as T cells and macrophages in tumor microenvironment. Paradoxical complex role of TGF- $\beta$ in tumor is documented, in an early stage of cancer, it acts as a tumor suppressor, promoting apoptosis and inhibiting cell cycle progression through P21 up-regulation and MYC down-regulation. In later stages of tumor it enhances immunosuppression by converting effector $\mathrm{T}$ cells in to regulatory $\mathrm{T}$ cells ( $\mathrm{T}$ 


\begin{tabular}{|c|c|c|}
\hline Cytokines & $\begin{array}{c}\text { Source } \\
\end{array}$ & Action \\
\hline IL-1 & $\begin{array}{c}\text { Monocytes } \\
\text { Macrophages } \\
\text { Endothelial cells } \\
\text { Neutrophils }\end{array}$ & $\begin{array}{c}\text { Angiogenesis } \\
\text { Immune suppression } \\
\text { Tumor progression }\end{array}$ \\
\hline TNF- $\alpha$ & $\begin{array}{l}\text { Macrophages } \\
\text { Mast cells } \\
\text { T and B cells }\end{array}$ & $\begin{array}{c}\text { Genetic mutation } \\
\text { Immune suppression } \\
\text { Angiogenesis } \\
\text { Invasion and metastasis }\end{array}$ \\
\hline IL-6 & $\begin{array}{l}\text { Dendritic cell } \\
\text { Macrophages } \\
\text { B-Iymphocytes }\end{array}$ & $\begin{array}{l}\text { Cell proliferation } \\
\text { Cell survival }\end{array}$ \\
\hline $\begin{array}{l}\text { IL-8 } \\
\text { IL-10 }\end{array}$ & $\begin{array}{c}\text { Macrophages } \\
\text { Mast cell } \\
\text { Macrophages } \\
\text { Monocytes } \\
\text { Dendritic cells } \\
\text { Granulocytes } \\
\mathrm{T} \text { and B cells }\end{array}$ & $\begin{array}{c}\text { Angiogenesis } \\
\text { Immune suppression } \\
\text { Cell survival } \\
\text { Cell proliferation }\end{array}$ \\
\hline TGF- $\beta$ & $\begin{array}{c}\text { T cells } \\
\text { Carcinoma associated fibroblasts } \\
\text { Tumor cells } \\
\text { Macrophages }\end{array}$ & $\begin{array}{l}\text { Epithelial mesenchymal } \\
\text { Transition (EMT) } \\
\text { Immune suppression }\end{array}$ \\
\hline IL-17 & $\begin{array}{l}\text { Macrophages } \\
\text { Mastr cells }\end{array}$ & $\begin{array}{c}\text { Immune suppression } \\
\text { Chronic inflammation } \\
\text { Angiogenesis } \\
\text { Tumor progression } \\
\end{array}$ \\
\hline
\end{tabular}

reg), tumor invasion and metastasis by inducing epithelial mesenchymal transition (EMT) through Smad, Slug and snail transcription factors. TGF- $\beta$ receptor mutation or deletion leading to poor prognosis in cancers such as oral squamous cell carcinoma, colorectal, gastric, prostate, non-small cell lung, breast, bladder cancer [24-26].

IL-17 is a pleiotropic, procarcinogenic cytokine is a subtype of CD4 $\mathrm{T}$ cells produced by CD4 Th17 cells, expressed by tumor associated macrophages involved in tumor progression, induced by IL-23 proinflammatory cytokine in tumor microenvironment. It is involved in promoting inflammation and angiogenesis by production of TNF- $\alpha$, IL- 6 and IL- $1 \beta$ induced activation of STAT3 and NF-KB transcription factors, promotes tumor progression in human carcinomas such as oral squamous cell carcinoma, non-Hodgkin's lymphoma, breast, colon, gastric, hepatocellular, melanoma, ovarian, pancreatic, prostate, renal cell, and small cell lung cancer [27-30] (Table1).

\section{Conclusion and Future Perspective}

Chronic inflammation promotes tumor initiation and progression by releasing inflammatory mediators such as cytokines (IL-1,IL-6, IL-10, TGF- $\beta$, IL-8 and TNF- $\alpha$ ) from innate and adaptive immune cells. Cytokines are chemical mediators, which acts as a messenger between immune, cancer and stromal cells to bring about cell proliferation, cell survival, immunosuppression, genomic instability, angiogenesis, invasion and metastasis by activating transcriptional factors such as $\left(\mathrm{NF}_{-\mathrm{K}} \mathrm{B}\right.$, STAT3, HIF$1 \alpha$ ). It acts as a biological markers, therapeutic target and prognostic markers in cancers. So, thorough understanding of cytokines, their role, and interaction with cancer cells needed for future perpective. Understanding of interaction of cytokines with immune cells, stroma and cancer cells in tumor microenvironment, their signaling pathway, role in tumor progression, helps in future diagnostic, therapeutic and prognostic purpose.

\section{Conflict of interest}

The author disclosed no conflict of interest during the preparation or publication of this manuscript.

\section{Financing}

The author disclosed that they did not receive any grant during conduction or writing of this study.

\section{Acknowledgements}

I would like to thank our institute colleagues for their support.

\section{Abbreviations}

$\mathrm{HGF}=$ hepatic growth factor, VEGF $=$ vascular endothelial growth factor, MMP-9 = matrix metaloproteinases-9, $\mathrm{NO}=$ nitric oxide, $\mathrm{ROS}=$ reactive oxygen species, $\mathrm{PDGF}=$ platelet derived growth factor, $\mathrm{EGF}=$ epidermal growth factor, FGF = fibroblast growth factor, TNF- $=$ tumor necrosis factor-alfa, IFN- $\beta=$ interferon-beta, IL-10 = interleukin 10, TGF- $\beta=$ transforming growth factorbeta, $\mathrm{PGE} 2$ = prostaglandin E2, IDO = indoleamine 2,3-dioxygenase, IL-2 = interleukin-2, IL-4 = interleukin-4, IL-6 = interleukin- 6 , IFN- $\gamma=$ interferongamma, $\mathrm{COX} 2$ = cyclo-oxygenase $2, \mathrm{NF}-\mathrm{KB}=$ Neuclear factor kappa B, IL-17 = interleukin-17, CD4+Th17 = CD4+T helper lymphocyte 17 , STAT3 $=$ signal transducer and activator of transcription 3, $\mathrm{bFGF}=$ basic fibroblast growth factor, MMPS = matrix metallo proteinases, HIF-1 = hypoxiainducible factor-alfa. Treg cell $=\mathrm{T}$ regulatory cell, TAM $=$ tumor associated macrophages, AP-1 = activator protein 1, EMT = epithelial mesenchymal transition, $\mathrm{MAPK}=$ mitogen-activated protein kinase, P13k = phosphatidylinositol 3-kinase, IL-8 = interleukin-8, LPS = lipopolysaccharide, Th2 cell $=\mathrm{T}$ helper 2 cell, IL-1 = interleukin-1 


\section{References}

[1] Landskron G, De la Fuente M, Thuwajit P, Thuwajit C, Hermoso MA. Chronic inflammation and cytokines in the tumor microenvironment. J Immunol Res 2014;2014:149185.

[2] Amedei A, Prisco D, D' Elios MM. The use of cytokines and chemokines in the cancer immunotherapy. Recent Pat Anticancer Drug Discov 2013;8:126-42.

[3] Sadaf EZ. Role of inflammatory cytokines in inflammation and cancer. J Public Health Biological Sci 2013;2:173-82.

[4] Lee S, Margolin K. Cytokines in cancer immunotherapy. Cancers (Basel) 2011;3:3856-93.

[5] Anestakis D, Petanidis S, Kalyvas S, Nday CM, Tsave O, Kioseoglou $\mathrm{E}$, et al. Mechanisms and applications of interleukins in cancer immunotherapy. Int J Mol Sci 2015;16:1691-710.

[6] Burkholder B, Huang RY, Burgess R, Luo S, Jones VS, Zhang W, et al. Tumor-induced perturbation of cytokines and immune cell networks. Biochim Biophys Acta 2014;1845:182-201.

[7] Hanahan D, Coussens LM. Accessories to the crime: functions of cells recruited to the tumor microenvironment. Cancer Cell 2012;21:30922.

[8] Paltridge JL, Belle L, Khew-Goodall Y. The secretome in cancer progression. Biochi Biophys Acta 2013;1834:2233-41.

[9] Zhong Z, Sanchez-Lopez E, Karin M. Autophagy, inflammation, and immunity: a Troika governing cancer and its treatment. Cell 2016;166:288-98.

[10] Haabeth OA, Bogen B, Corthay A. A model for cancer suppressive inflammation. Oncoimmunology 2012;1:1146-56.

[11] Pages F, Galon J, Dieu-Nosjean MC, Tartour E, Sautes-Fridman C, Fridman WH. Immune infiltration in human tumors: a prognostic factor that should not be ignored. Oncogene 2010;29:1093-102.

[12] Schetter AJ, Heegaard NH, Harris CC. Inflammation and cancer: interweaving microRNA, free radical, cytokine and p53 pathways. Carcinogenesis 2010;31:37-49.

[13] Fridman WH, Pages F, Sautes-Fridman C, Galon J. The immune contexture in human tumors: Impact on clinical outcome. Nat Rev Cancer 2012;12:298-396.

[14] Senovilla L, Vacchelli E, Galon J, Adjemian S, Eggermont A, Fridman WH, et al. Trial watch: Prognostic and predictive value of the immune infiltrate in cancer. Oncoimmunology 2012;1:1323-43.
[15] Shalapour S, Karin M. Immunity, inflammation, and cancer: an eternal fight between good and evil. J Clin Invest 2015;125:3347-55.

[16] Alvaliotis IL, Pateras IS, Papaioannou M, Glytsou C, Kontzoglou $\mathrm{K}$, Johnson EO, et al. How do cytokines trigger genomic instability? J Biomed Biotechnol 2012;2012:536761.

[17] Vesely MD, Kershaw MH, Schreiber RD, Smith MJ. Natural innate and adaptive immunity to cancer. Annu Rev Immunol 2011;29:235-71. [18] Meulmeester E, Ten Dijke P. The dynamic roles of TGF- $\beta$ in cancer. J Pathol 2011;223:205-18.

[19] Shrihari TG, Vasudevan V, Manjunath V, Devaraju D. Potential corelation between chronic periodontitis and cancer - an emerging concept. Gulf J Oncolog 2016;1:20-4.

[20] Korniluk A, Koper O, Kemona H, Dymicka-Piekarska V. From inflammation to cancer. Ir J Med Sci 2017;186:57-62.

[21] Carmeliet P, Jain RK. Molecular mechanisms and clinical applications of angiogenesis. Nature 2011;473:298-307.

[22] Tecchio C, Scapini P, Pizzolo G, Cassatella MA. On the cytokines produced by human neutrophils in tumors. Semin Cancer Biol 2013;23:159-70.

[23] Chai EZ, Siveen KS, Shanmugam MK, Arfuso F, Sethi G. Analysis of the intricate relationship between chronic inflammation and cancer. Biochem J 2015;468:1-15.

[24] Wilke CM, Kryczek I, Wei S, Zhao E, Wu K, Wang G, et al. Th17 cells in cancer; help or hindrance? Carcinogenesis 2011;32:643-9.

[25] Zhang L, Feng D, Yu LX, Tsung K, Norton JA. Preexisting antitumor immunity augments the antitumor effects of chemotherapy. Cancer Immunol Immunother 2013;62:1061-71.

[26] Chimal-Ramirez GK, Espinoza-Sanchez NA, Fuentes-Panama EM. Protumor activities of the immune response: insights in the mechanisms of immunological shift, oncotraining, and oncopromotion. J Oncol 2013;2013:835956.

[27] Marata M, Thanan R, Ma N, Kawanishi S. Role of nitrative and oxidative DNA damage in inflammation-related carcinogenesis. J Biomed Biotechnol 2012;2012:623019.

[28] Shrihari TG. Dual role of inflammatory mediators in cancer. Ecancermedicalscience 2017;11:721.

[29] Lippitz BE. Cytokine patterns in patients with cancer: a systematic review. Lancet Oncol 2013;14:218-28.

[30] Diakowska D. Cytokines association with clinical and pathological changes in esophageal squamous cell carcinoma. Dis Markers 2013;35:883-93. 